\title{
PARTIAL REPLACEMENT OF CEMENT WITH BAGASSE ASH IN HOT MIX ASPHALT
}

\author{
A. A. Murana ${ }^{1,{ }^{*}}$ and L. Sani2 \\ 1 Department of Civil EngineEring, Ahmadu Bello University, Zaria, Kaduna STATE. NiGERIA \\ 2 Department of Civil EngineEring, Kaduna PolyteChnic, KAduna, KadunA State. NIGERIA \\ Email addresses: 1 fatinoyi2007@yahoo.co.uk,2lawalyt@gmail.com
}

\begin{abstract}
Several waste and used materials from different sources are generated every day in large quantities. However, these wastes have been found to be useful in the stabilization and/or improvement of construction materials. Amongst these techniques is the use of Bagasse Ash (BA). It is in this light that a laboratory based investigation for the replacement of cement with BA in Hot Mix Asphalt (HMA) was conducted. Tests on the suitability of materials used and their performance in terms of known engineering properties was carried out. Bitumen content of $4.5 \%$, $5.5 \%, 6.5 \%$ and $7.5 \%$ was adopted. The focus involves the partial replacement of cement with BA in the following order, 0\% (control), 10\%, 20\%, 30\%, 40\% and 50\%. Seventy-two mix specimens were produced. The results obtained shows that the Cement/BA mixes exhibit satisfactory trend result with an average bitumen content of 5.5\%.The results obtained shows that stability increases as BA content decreases, flows at 5.5\% bitumen Content was observed to be fairly constant at roughly $2.5 \mathrm{~mm}$, the per cent air voids in the mix decreases with increasing bitumen content, the VMA values all fall within specification except for $30 \%$ BA replacement, the VMA value was $16 \%$ at 5.5\% of Bitumen Content. Therefore, the Cement/BA mixes exhibit satisfactory trend results with an average Bitumen content of $5.5 \%$.
\end{abstract}

Keywords: Hot Mix Asphalt, Marshall Test, Bitumen, Bagasse Ash, Strength properties.

\section{INTRODUCTION}

Asphalt concrete is a mixture of aggregate, binder (bitumen) and filler (majorly cement), used for construction and maintenance of all kinds of roads, parking areas, playground and sport areas [1].

Asphaltic pavement design is incomplete or becomes unstable without filler. Mineral filler consists of very fine, inert mineral matter that is added to the Hot Mix Asphalt (HMA) to improve the density and strength of the mixture. Filler is generally selected on the basis of its ability to increase the stiffness of the binder mastic or improve adhesion between the binders and aggregate [2]. Geotechnical analysis is performed in pavement analysis and design system to determine the strength and stiffness of the sub-grade. The material characterization, load characterization and mechanistic analysis and behaviour functions are important factors to consider in pavement analysis and design system method [3]

*Corresponding author, Tel: +234-803-637-6697
In civil engineering works, various waste products have been used for several purposes amongst which are stabilization of soil and replacement of filler or binder materials. These wastes utilization would not only be economical but may also result to foreign exchange earnings and environmental pollution control [4].

In highway construction technology, efforts are being made in the area of utilizing waste materials instead of discarding or incinerating them. Such wastes include industrial, Agricultural and Municipal solid waste [5]. Earlier research has investigated the performance of asphalt concrete containing Metakaolin partially replaced with cement [6]. They found out that at varying percentages of bitumen content, the stability, flow, voids in mixed aggregates and void in the mix meets the standard specified with an optimum bitumen content of 5.5\%.

Recently Bagasse Ash (BA), a readily available agricultural/industrial waste material has found useful application in engineering and other field of 
studies. Sugarcane Bagasse (SCB) is a fibrous wasteproduct of the sugar refining industry, along with ethanol vapour. Its analysis from sugar industry shows that it contains unburned carbon along with the other constituents present in Portland cement. BA can replace some of the raw materials; reduce the energy cost and increasing revenue from the cement industry [7].

The use of BA as a supplementary cementitious material to partially replace Ordinary Portland Cement (OPC) not only helps reduce methane emissions from dispose of organic waste and reduce the production of cement, which is in famous for its high energy consumption and $\mathrm{CO}_{2}$ emission, but also can improve the compressive strength of cement mixed materials [8].

As stated by Cordeiro et al. [9], the improved compressive strength depends on both physical and chemical effects of the SCB ash. The physical effect of the filler is concerned with the packing characteristics of the mixture, which in turns depends on the size, shape and texture of SCB ash particle. The chemical effects relates to the ability of the BA to provide reactive siliceous and aluminous compounds to participate in the pozzolanic reaction with calcium hydroxide and water.

Laboratory study on the influence of three compactive efforts on the strength properties of treated black cotton soil shows that the tropical black cotton clay treated with a maximum of $10 \%$ BA by weight of dry soil indicated that the strength properties increased with higher compactive effort [10].

\section{MATERIALS AND METHODS}

\subsection{Materials}

Materials used in the Mix design of asphalt includes filler materials (BA and OPC), aggregates (fine and coarse) and binder (bitumen). The fibrous residue after crushing and extraction of juice fromsugar cane was obtained from Kura in Kano State where it is in abundance after which it was burnt in open air to obtain its ash. The fresh coarse and fine aggregate were obtained from Zaria in Kaduna State. The OPC was of Dangote brand and obtained from Samaruopen marketin Zaria, Kaduna State. The bitumen used was obtained from Nigeria National Petroleum Cooperation (NNPC) in Kaduna State.

\subsection{Methods}

The methodology involves the experimental tests carried out to determine the physical properties of bitumen, coarse aggregate, fine aggregate, cement and the chemical properties of BA. The tests carried out on BA and the components of HMA are as follows:

1. Tests on Bagasse Ash: Chemical Composition (using mini pal which is a compact energy dispersive Xray spectrometer), Particle Size Distribution and Specific gravity [11].

2. Test on aggregates: impact value/hardness test, crushing value, size and gradation [12] and specific gravity [11]

3. Tests on bitumen: Penetration, Solubility, Flash and fire point, Viscosity and Ductility tests [12].

4. Experimental test on cement: Initial and Final setting time and Soundness test [13].

5. Marshall Test [14]

\section{RESULTS AND DISCUSSIONS}

\subsection{Tests on Aggregates (Coarse, Fine and Filler)}

Table 1 shows the strength properties which are measures of mechanical properties (crushing and impact tests) of the aggregate and specific gravity (measure of aggregates and filler density).

\section{Table 1: Comparison of test result on aggregates and} filler with standard specifications

\begin{tabular}{lcc}
\hline Property & Result & Code Specification \\
\hline Aggregate Crushing Value & $22.12 \%$ & $<30$ \\
Aggregate Impact Value & $21.31 \%$ & $<30$ \\
Specific Gravity (Coarse) & 2.5 & $2.6-2.9$ \\
Specific Gravity (Fine) & 2.62 & $2.6-2.9$ \\
Specific Gravity (Bagasse) & 2.85 & 2.85 \\
\hline
\end{tabular}

The results obtained from the tests conducted on aggregates all falls within the specified values quoted in the code of specifications as such the aggregate is suitable for HMA design.

\subsection{Particle Size Distribution Curves for Aggregates}

The results of particle size distribution test performed on the coarse and fine aggregates are presented in Figures 1 and 2 respectively.

Coarse aggregate can be defined as all materials retained in sieve $2.36 \mathrm{~mm}$ sieve. Since the coarse aggregate used for this study has zero percent $(0 \%)$ passing sieve $2.36 \mathrm{~mm}$, it can be inferred that the aggregates meets the requirements. Also fine aggregate is defined as all materials passing $2.36 \mathrm{~mm}$ sieve size. Since the fine aggregate used for this study satisfies this requirement, then it is suitable for use in asphalt concrete. 


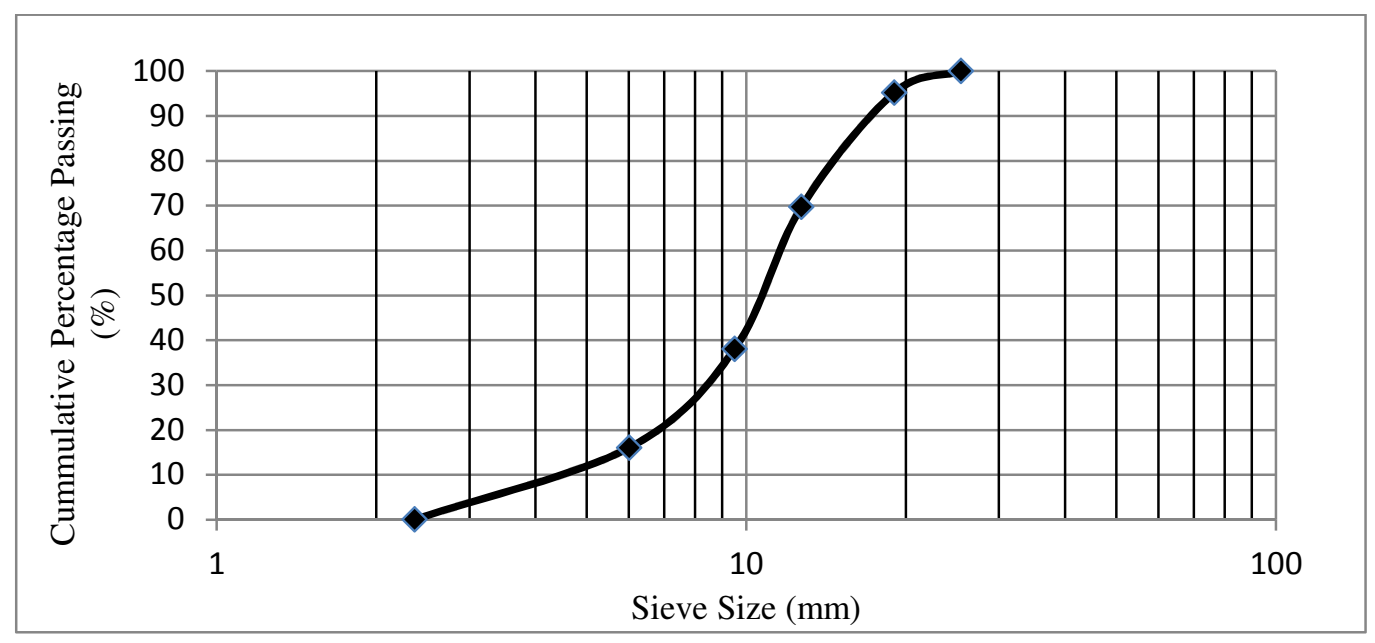

Figure 1: Particle size distribution curve for coarse aggregate

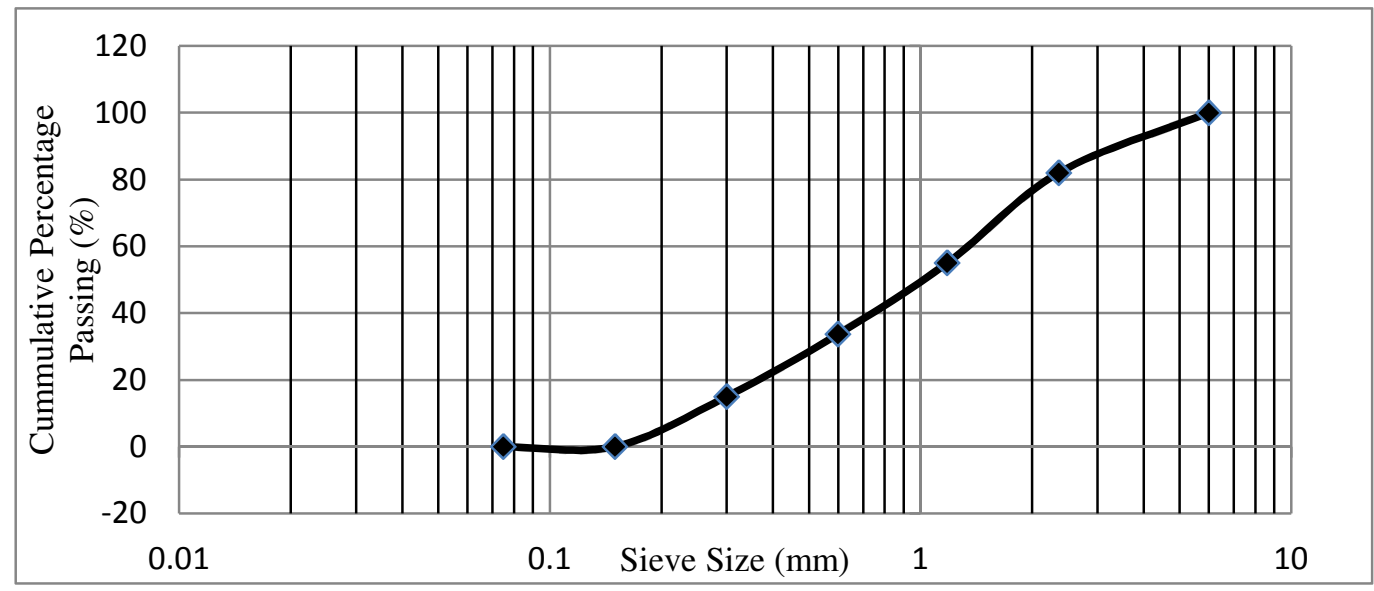

Figure 2: Particle size distribution curve for fine aggregate

\subsection{Tests on Bitumen}

The test results obtained are compared with those specified by the relevant codes so as to see the suitability or otherwise of the tested materials for HMA pavement design. The comparison was as shown in Table 2. From the results, it can be seen that the penetration, viscosity, flash and fire point, ductility, solubility and specific gravity of the bitumen used fall within the range specified by the code. Therefore, the material can be used in HMA design.

\subsection{Tests on Bagasse Ash}

The result of chemical composition analysis conducted of bagasse ash is as shown in Table 3 and its particle size distribution curve is shown in Figure 3. According to ASTM standard which specifies a material having combined weight of silica, aluminum and iron oxides of $50 \%$ by weight of fraction can be deduced to be class $\mathrm{C}\left(\mathrm{SiO}_{2}+\mathrm{Al}_{2} \mathrm{O}_{3}+\mathrm{Fe}_{2} \mathrm{O}_{3}=53.4 \%\right)$ and can be used as mineral filler in HMA design as a partial replacement of cement. The result of the particle size distribution is as shown in Figure 3. It was observed that about $65 \%$ of $\mathrm{BA}$ passed the $0.075 \mathrm{~mm}$ sieve which signifies that the ash is suitable for use in HMA.

Table 2: Comparison of test results on bitumen with standard specifications

\begin{tabular}{lll}
\hline Test & Result & Code Specification \\
\hline Penetration at $25^{\circ} \mathrm{C}$ & $92 \mathrm{~mm}$ & $80-100(\mathrm{~mm})$ \\
Flash \& Fire Point $(\mathrm{min})$ & $243{ }^{\circ} \mathrm{C}$ & $219{ }^{\circ} \mathrm{C}$ \\
Solubility in CCL4 & $99 \%$ & $99 \%$ \\
Specific gravity & 1 & $0.97-1.02$ \\
Ductility at $25^{\circ} \mathrm{C}$ & $75 \mathrm{~cm}$ & $75 \mathrm{~cm}$ \\
Viscosity at $60^{\circ} \mathrm{C}$ & $192 \mathrm{~mm}^{2} / \mathrm{s}$ & $120-250\left(\mathrm{~mm}^{2} / \mathrm{s}\right)$ \\
\hline
\end{tabular}

Table 3: Chemical composition of bagasse ash

\begin{tabular}{llllll}
\hline $\begin{array}{l}\text { Comp } \\
\text { onent }\end{array}$ & $\begin{array}{l}\text { Weight of } \\
\text { fraction \% }\end{array}$ & $\begin{array}{l}\text { Comp } \\
\text { onent }\end{array}$ & $\begin{array}{l}\text { Weight of } \\
\text { fraction \% }\end{array}$ & $\begin{array}{l}\text { Comp } \\
\text { onent }\end{array}$ & $\begin{array}{l}\text { Weight of } \\
\text { fraction \% }\end{array}$ \\
\hline $\mathrm{Al}_{2} \mathrm{O}_{3}$ & 5.5 & $\mathrm{SiO}_{2}$ & 38 & $\mathrm{Fe}_{2} 0_{3}$ & 9.9 \\
$\mathrm{P}_{2} 0_{5}$ & 3.14 & $\mathrm{~K}_{2} \mathrm{O}$ & 15.3 & $\mathrm{SO}_{3}$ & 2.61 \\
$\mathrm{Re}_{2} \mathrm{O}_{7}$ & 0.02 & $\mathrm{TiO}_{2}$ & 1.62 & $\mathrm{CaO}$ & 9.25 \\
$\mathrm{~V}_{2} \mathrm{O}_{5}$ & 0.079 & $\mathrm{Cr}_{2} \mathrm{O}_{3}$ & 0.071 & $\mathrm{MnO}$ & 0.32 \\
$\mathrm{NiO}$ & 0.084 & $\mathrm{CuO}$ & 0.073 & $\mathrm{ZnO}$ & 0.23 \\
$\mathrm{BaO}$ & 0.53 & $\mathrm{Cl}$ & 3.52 & $\mathrm{Rb}_{2} \mathrm{O}$ & 9.7 \\
\hline
\end{tabular}




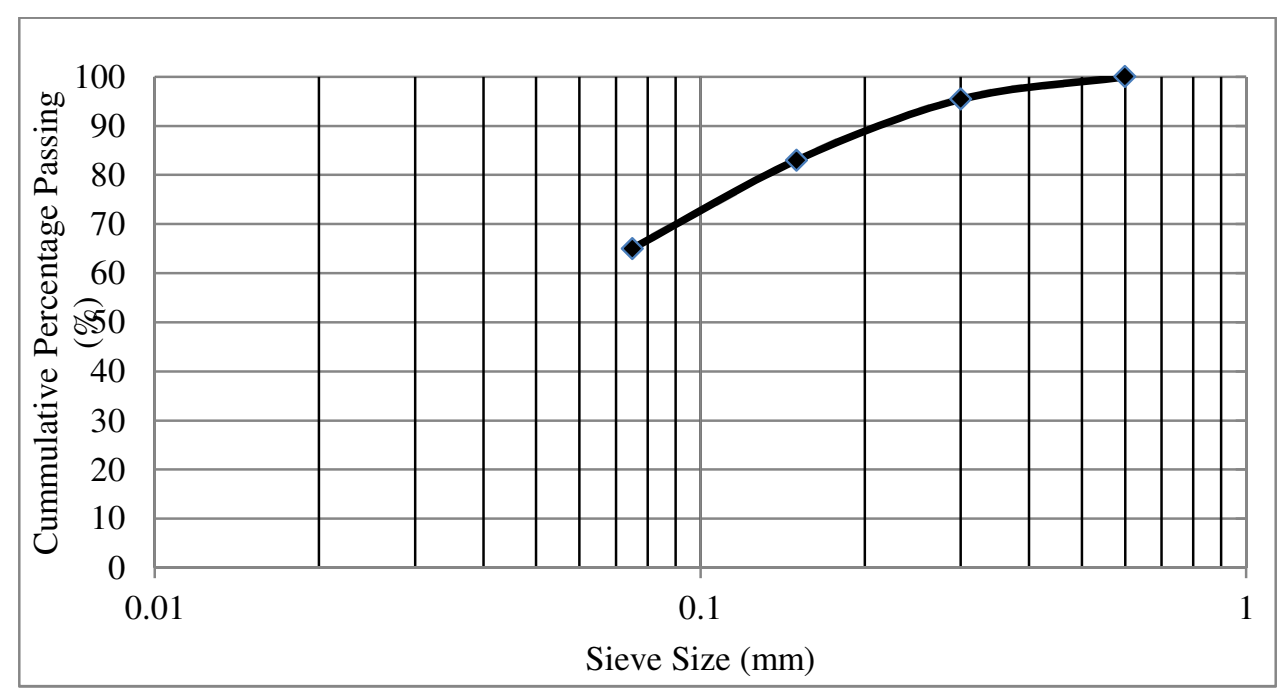

Figure 3: Particle size distribution curve for $B A$

\subsection{Tests on Cement}

The results obtained compared with standard from code of practice were as shown in Table 5. It was observed that the OPC used conforms to the standard stipulated in the specification. Hence, the cement is suitable for use in Civil Engineering work.

Table 5: Comparison of test result on cement with standard specifications

\begin{tabular}{lll}
\hline Test & Result & Code Specification \\
\hline Initial Setting Time & $68 \mathrm{~min}$ & $>45 \mathrm{~min}$ \\
Final Setting Time & $3 \mathrm{hrs} 75 \mathrm{~min}$ & $<10 \mathrm{hrs}$. \\
Soundness & $3.1 \mathrm{~mm}$ & $<10 \mathrm{~mm}$ \\
Specific Gravity & 2.44 & 3.15 \\
\hline
\end{tabular}

\subsection{Marshall Test}

The variation of Marshall Properties with bitumen content for mixes containing varying proportions of fillers are shown in Figures 4 to 9 from which the Marshall Test results are discussed.

Figure 4 shows the relationship between Stability and Bitumen Content. Stability increases as BA decreases beyond a bitumen content of $6.5 \%$. From Figure 5,

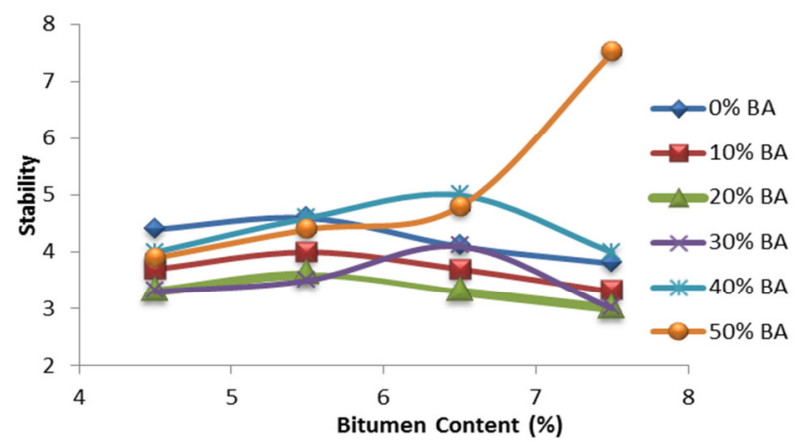

Figure 4: Variation of stability with bitumen content flow values for 0 and 10 percent BA happen to be perfect while others fail. It can also be deduced that Flows at $5.5 \%$ bitumen content, are fairly constant at roughly $2.5 \mathrm{~mm}$. The curves (see Figure 6) for unit weight (density) of total mix follow the same trend as that of the stability curve. According to design criteria stated in Asphalt Institute Marshall design, percent air voids in the mix decreases with increasing bitumen content, and most of these values fall within 3 to $5 \mathrm{~mm}$. 30 and $50 \%$ of BA completely fall out of range (see Figure 7).

According to Asphalt Institute [15] Marshall Design criteria, the minimum void in mineral aggregate is $15 \%$, since the maximum particle size used in this work is $12.5 \mathrm{~mm}$. The voids in mineral aggregate (VMA) values of Figure 8 all fell in range, except for that of $30 \%$ BA. It also shows that percent voids increases with increasing bitumen content. The value of $5.5 \%$ of bitumen content gave rise to approximately constant VMA value of $16 \%$. The combined graphs of void filled with bitumen (VFB) with bitumen content (see Figure 9), show how VFB values increase with increasing bitumen content. But, VFB value of $50 \%$ BA with bitumen content above $6.4 \%$ decreases instead.

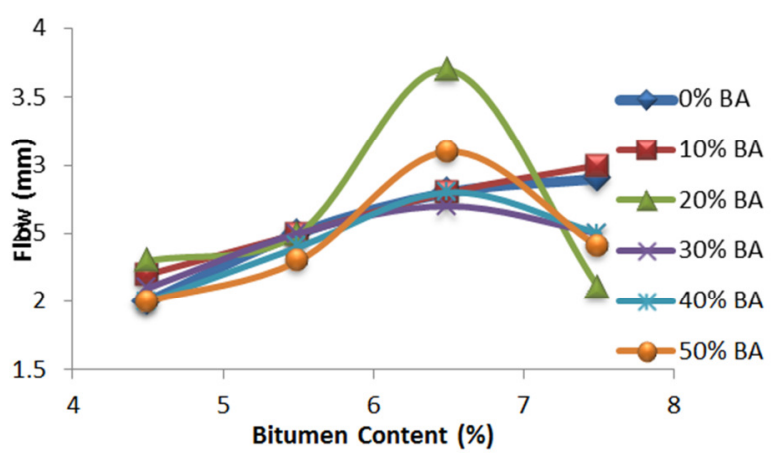

Figure 5: Variation of flow with bitumen content

Vol. 34 No. 4, October 2015 


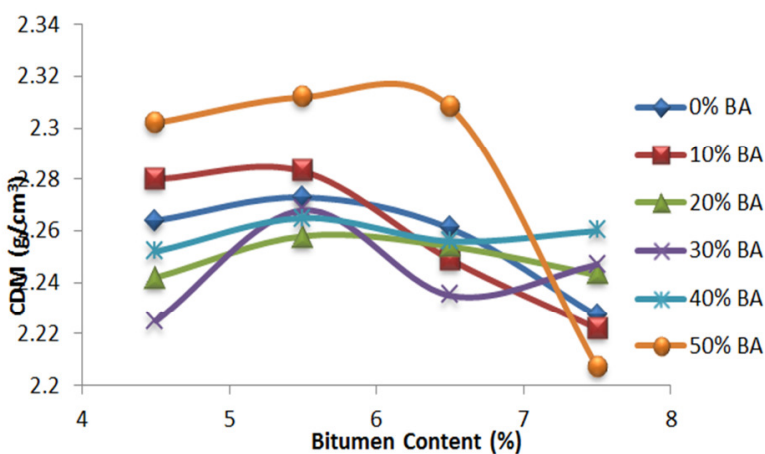

Figure 6: Variation of Compacted Density of the Mix (CDM) with bitumen content

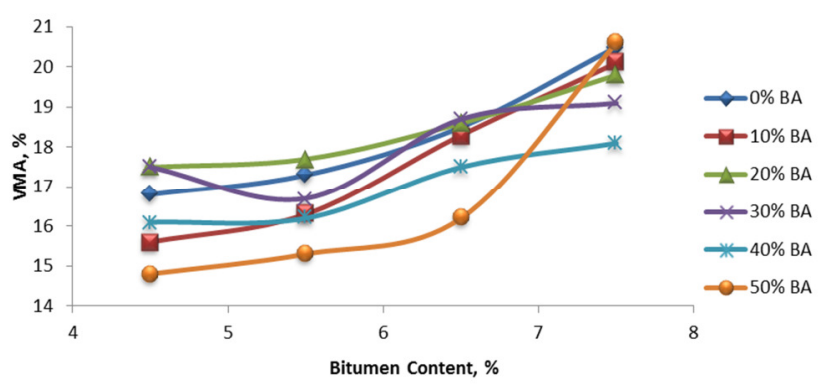

Figure 8: Variation of voids in mineral aggregate (VMA) with bitumen content

\section{CONCLUSION}

1. BA as a partial replacement for cement will help to solve environmental problems encountered in urban settings where Bagasse is disposed; hence this can help in the actualization of the phrase "waste to wealth".

2. The desirable properties of aggregates used in this study fell within the value specified by the relevant standards. Also, the required properties of bitumen as a binder also conform to the standard specified by the relevant codes. Therefore, they can be used in the design of asphalt pavement.

3. The recommended properties of mineral filler in terms of pozzolanic characteristics and fineness was met by the BA since the combined percentage of silica, aluminium and iron oxides meets the specification in ASTM standard.

4. The mix containing $10 \% \mathrm{BA}$ and $90 \% \mathrm{OPC}$ at varying percentages of bitumen content have values which meet the standard specified in Asphalt Institute for strength criteria.

5. The Optimum BA content to be partially replaced with OPC in asphalt concrete mix should be $10 \%$.

\section{RECOMMENDATION}

1. From the investigations conducted, it will be highly satisfactory to partially replace BA up to $10 \%$ content with OPC as filler in asphalt mix design. It

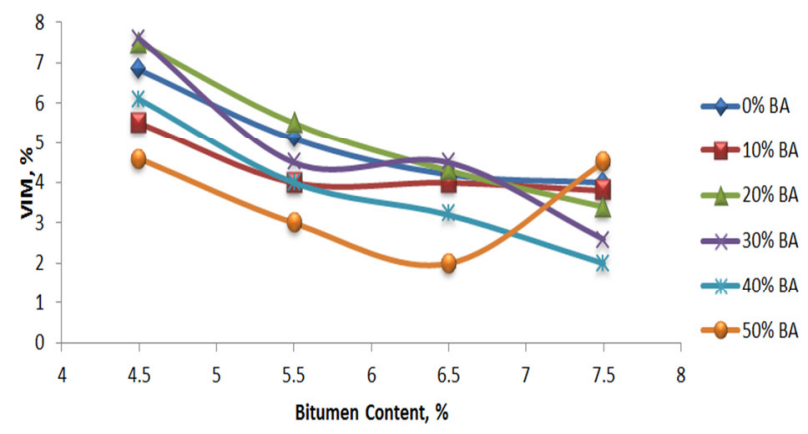

Figure 7: Variation of Void in the Mix (VIM) with bitumen content

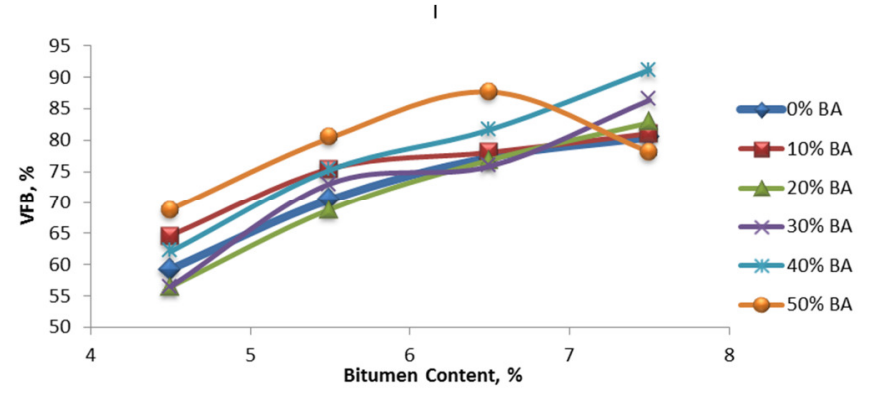

Figure 9: Variation of void filled with bitumen (VFB) with bitumen content

is recommended that further research should be carried out to investigate the cost effectiveness and affordability of the BA for use as fillers in asphalt concrete mix.

\section{REFERENCES}

[1] A. A. Murana, A. A. Ahmed and F. T Jegede, "Suitability of Bagasse Ash as a Filler Material in Hot Mix Asphalt HMA) Concrete," In LARYEA, S, and AYEPONG, S. (Eds) Procs 5thWest Africa Built Environent Research (WABER) conference, Ghana, 1013.

[2] U.S. Imam, Evaluation of the Effect of Bagasse ash as Filler in Hot Mix Reycled Asphalt Pavement, Zaria: Unpublished Msc Thesis, Department of Civil Engineering Ahmadu Bello University, Zaira, Kaduna Nigeria, 2010.

[3] A. A. Murana, A. T. Olowosulu and H. S. Otuoze, "Minimum Thresholds of Monte Carlo Cycles for Nigerian Empirical-Mechanistic Pavement Analysis and Design System," Nigerian Journal of Technology, vol. 31 , no. 3, p. $321-328,2012$

[4] V. S. Aigbodion, S, B. Hassan, S. O, Olajide, O. J. Agunsoye, A, S, AbdulRahaman and G. E. Okafor, "The use of Rice Husk ash as an Aggregate for foundry sand production in Nigeria, "in Proceedings of the Nigeria Metallurgical Society (NMS), Annual Conference, 2008.

[5] A. A Murana, A. T. Olowosulu, F. T. Jegede, A. A. Ahmed and H, A. Ahmed, "Evaluating the Strength of 
Bagasse Ash as Filler in Hot Mix Asphalt Design, " in Procs 1st NIQS Annual Research Conference (AnReCon), Nigerian Institute of Quantity Surveyors, Abuja 2013.

[6] A. A. Murana, A. T. Olowosul and S, Ahiwa, "Performance of Metakaolin as Partial Replacement of Cement in Hot Mix Asphalt," Nigerian Journal of Technology, Vol. 33, no, 3 PP. 387, 2014.

[7] T., S. Mohammed, A. Kurshid and N Amin, "Physiochemical Study of Bagasse and Bagasse ash from the Sugar Industries of North. West Frontier Province (NWFP), Pakistan and its Recycling in Cement Manufacturing." J. Chem, Soc. Pac, Vol. 31, No. 3 pp. 375-378, 2009.

[8] Sirirat and W. Supaporn, "Pozzolanic Activity of Industrial Sugar Cane Bagasse ash." Suranaree J. Sci. Technol., Vol. 17, No. 4 pp349 - 357, 2010.

[9] G, C., Cordeiro, F. Toledo, L., M., Tarvares and E. M.R. Fairbairn, "Pozzolanic activity and Filler Effect of Sugar Cane Bagasse Ash in Portland Cement and
Lime Mortars," International Journal of Cement Composites and Lightweight Concrete, Vol. 30, No, 5, pp $361-463,2008$.

[10] K. J. Osinubi and S.A. Thomas, "Influence of Compactive Efforts on Bagasse Ash Treated Black Cotton Soil," Nigerian Journal of Soil and Environmental Research, Vol. 7, pp, 92 - 101, 2007.

[11] ASTM, Annual Book of ASTM Standards, Soils and Rock: Vol. 04.08, West Conshohocken, Pa., 2000 American Society for Testing and Materials, 2000.

[12] BS812M, Method for Sampling and Testing of Minerals Aggregate, Sand and Fillers, BS House 2, Park Street London: British Standard, 1990.

[13] BS: EN196-3, Method of Testing Cement, Determination of Setting Time and Soundness, BS House 2, Park Street London: British Standard, 1995.

[14] A. I, "Principles of Construction of Hot Mix Asphalt Pavements, Manual Series, No. 22 (MS-22)," Asphalt Institute, Maryland, 20740, USA, 1983. 